\title{
A Case Study to Setup Optimum Process Parameters in Thermal Deburring for Removing the Burr in Barrel of Fuel Injector Pump Using Taguchi Approach.
}

\author{
Prathap.R ${ }^{1}$, B.V.Raghavendra ${ }^{2}$, Pradeep.B.Shetty ${ }^{3}$ \\ ${ }^{I}$ (M.Tech-scholar, JSS Academy of Technical Education, Bangalore-India \\ 2(Assistant professor, Department of Mechanical Engineering, JSS Academy of Technical Education, \\ Bangalore-India \\ ${ }^{3}$ (Senior engineer, Manufacturing of Elements-Engineering (MFE-E), Bosch Ltd. Bangalore-India.
}

\begin{abstract}
Deburring is the finishing technique that is very essential for the manufacturing of precise components. Deburring process with greater efficiency and full automation is an extremely difficult task. Thermal deburring offers a potential solution to such problems. For successful utilization of thermal deburring, more intensive research including parameters analysis of the process is still required. The parameters which affect the performance of thermal deburring are mixture ratio of oxygen \& hydrogen gas, pressure of oxygen \& hydrogen gas mixture, Impulse of the chamber and size of the burr. A case study is conducted to find the optimum process parameters for thermal deburring using taguchi approach.
\end{abstract}

Key words - Deburring, Thermal deburring, Optimization, Taguchi approach

\section{INTRODUCTION}

Burr is the undesirable projection of material formed as the result of plastic flow from a cutting or shearing operation (Ko and Dornfeld, 1991)[1]. Although burrs were considered a secondary operation within the machine processes, several aspects have been modifying the way burrs are handled during the machine processes. Deburring processes have been identified as the bottleneck in many machine industries (Balasubramaniam et all, 1998)[2]. The burr removal methods can induce dimensioning errors to the work piece if improperly executed (Dornfeld and Lisiewicz,1992)[3]. Finally, burrs may cause problems in further processes, such as handling and assembling operations. There is no standard procedure to remove burrs having different shape and dimensions. For removing burrs of different sizes and shapes, there are number of conventional processes available. Conventional deburring processes necessitate time, labour and other associated costs. Thermal deburring is found to offer the potential solution to these problems(ASM Handbook Volume 16, Machining 1990)[4].

Thermal Deburr (TD), as the name implies, is a manufacturing process utilizing heat energy to remove burrs. They are placed inside a very thick walled steel chamber. The sealed chamber is pressurized with a mixture of combustible gas. The gaseous mixture is ignited with an electric ignition device creating a powerful explosion. The explosion creates a very intense heat approaching several thousand degrees Fahrenheit within fractions of a second. This intense heat energy will attack anything with a high surface area to mass ratio.

Thermal deburring machine is the best solution for removing all internal and external burrs simultaneously in a single operation(Kennametal Extrude Hone, $\mathrm{GmbH}$ )[5]. Thermal deburring is unique among material removal processes primarily because it removes burrs and flash simultaneously throughout the work piece, including internal and externallocations. (WWW.EXTRUDEHONE.COM)[6].

Thermal Deburring will not change any dimensions, surface finishes, or material properties of the parent part when performed properly with adequate fixtures.( John Halladay, 2011)[7].However it is important to find out the optimal process parameters that are capable of removing high amount of burr.

A case study has been conducted at M/s Bosch Ltd. Bangalore to reduce the rejection of barrel by using the thermal deburring method and to setup optimum process parameters using Taguchi approach.

The high pressure fuel injector pump performs its function through pumping elements consisting of a number plunger/barrel assemblies corresponding to a number of cylinders in a given engine. Fuel delivered by the supply pump flows through a fuel gallery along the length of high pressure pump and is introduced into plunger or barrel assembly via one or two fill ports. Fuel delivered by the supply pump flows through a fuel gallery along the length of high pressure pump and is introduced into plunger or barrel assembly via one or two fill ports. 


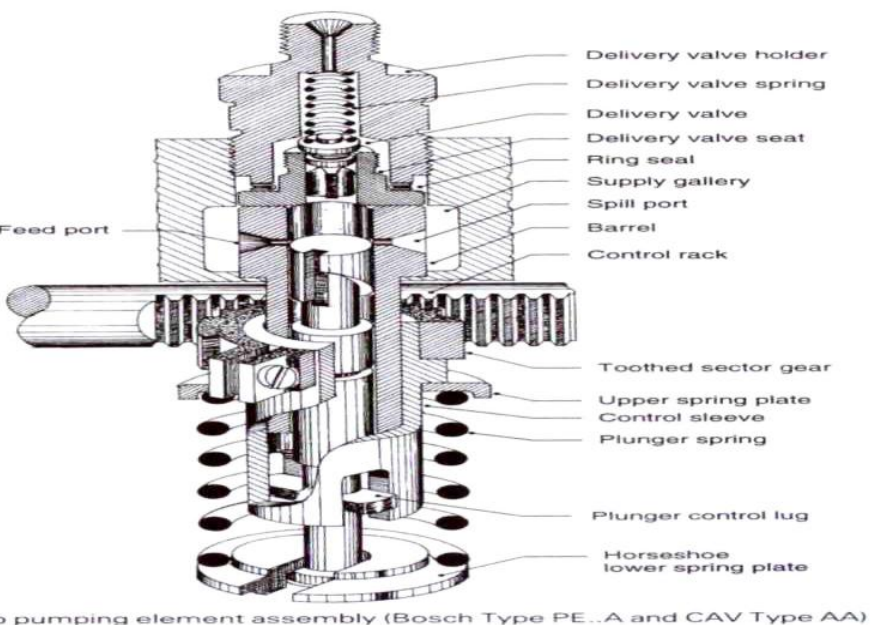

Fig. 1 Fuel injector pump

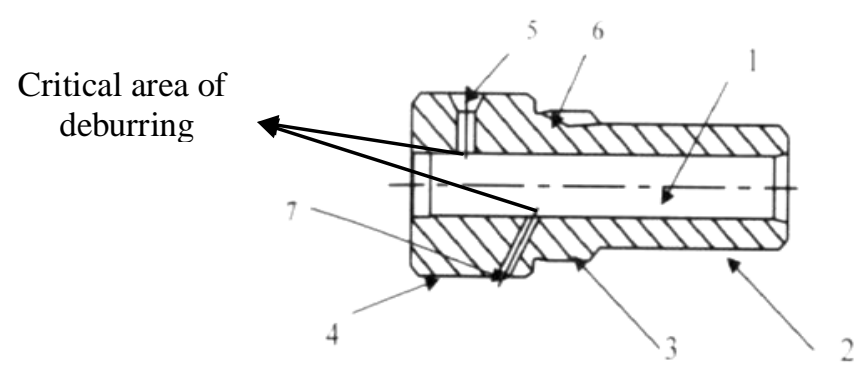

Fig. 2 Barrel

\section{Barrel}

The parts of Barrel are,

1. Main Bore.

2. Shaft

3. Step

4. Collar

5. Inlet hole

6. Fixing slot

7. Leak oil hole/excess oil vent

It is a component inside which plunger reciprocates. The barrel consists of two parts one is head portion and another is shaft portion. It has an inlet port and a bypass port (spill port). When the plunger is at BDC, fuel enters into the barrel through inlet port and excess fuel leaks out through spill port.

In this research, thermal deburring of the cross holes of component Barrel is performed. Efforts are taken to optimize the process parameters with considering characteristics like mixture ratio of oxygen \& hydrogen gas, pressure of oxygen \& hydrogen gas mixture, Impulse of the chamber and size of the burr. Verification experiment is carried out additionally to verify the predicted results at optimum level.

\section{LITERATURE REVIEW}

Deburring is considered to be very integral part of any machining or manufacturing process. Any process where there is a shearing or cutting or machining operation, burrs are automatically formed due to these process. There are many ways of deburring to remove the burr, they are conventional deburring process namely manual deburring, hand deburring etc and non-conventional deburring process like thermal deburring, electrochemical deburring, abrasive jet deburring etc. Now let us consider few of them,

\subsection{Magnetic abrasive finishing method (MAF):}

MAF is based on the magnetization property of ferromagnetic iron and the machining property of abrasives, the limitations of this process is that it Leaves behind abrasion marks on the surface of the deburred part. [9] 


\subsection{Thermal energy method (TEM):}

TEM also known as thermal deburring, it deburrs multiple surfaces at the same time.. It is the fastest burr removal process, requiring only 20 milliseconds to remove a burr. Its limitations are Initial investment is high.[10]

\subsection{Cryogenic deburring:}

Cryogenic deburring is a cryogenic process work at low temperatures (approximately-195 $\left.\mathrm{C}\left(-319.0^{\circ} \mathrm{F}\right)\right)$ is achieved using liquid nitrogen, liquid carbon dioxide, or dry ice. Its are Brittleness property of the material increase and micro cracks are formed on the surface [11].

\subsection{Manual deburring:}

Manual deburring results in inconsistent quality. Repeatability is hard to achieve as it is done manually

\subsection{Electro-chemical deburring (ECD):}

ECD can be used to deburr on a particular area, while the rest of the work piece is unaffected. It has its Limitations; Operation time is high compared to other methods. Higher burr height means more deburring time.[13]

\subsection{Design of Experiments (DOE):}

DOE ,Taguchi (1991) method is a widely used approach for robust design, which utilizes an orthogonal array $(\mathrm{OA})$ to obtain dependable information about the design parameter with minimum time and resources, and adopts signal-to-noise $(\mathrm{S} / \mathrm{N})$ ratio to interpret experimental data and optimize performance. [14]

\section{PROBLEM DEFINITION}

The present reamer tool deburring operation of the cross holes of the barrels causes lines/patches on the inside of the bore which is a major causes for rejection in about nearly $13 \%$ rejection of the barrels. There is a scope for improvement for reducing rejection by changing the deburring process to thermal deburring and finding the optimal process parameters for conducting thermal deburring operation.

\section{METHODOLOGY}

Conducting an experimentation to find out the optimal process parameters for Thermal deburring process.

The experiment is conducted by varying different controllable parameters such as mixture ratio of oxygen \& hydrogen gas $(\mathrm{O} 2+\mathrm{H})$, pressure of oxygen \& hydrogen gas $(\mathrm{O} 2+\mathrm{H})$, mixture, Impulse of the chamber and size of the burr.

\subsection{Design of Experiments:}

Table 1 Control factors and their levels

\begin{tabular}{|c|c|c|c|c|}
\hline \multirow{2}{*}{ Symbol } & Factors & \multicolumn{3}{|c|}{ Levels } \\
\cline { 3 - 5 } & & Level 1 & Level 2 & Level 3 \\
\hline A & $\begin{array}{c}\text { Mixture ratio of } \\
\text { O2+H gas }\end{array}$ & $\begin{array}{c}50+50 \\
(\mathrm{O} 2+\mathrm{H})\end{array}$ & $\begin{array}{c}40+60 \\
(\mathrm{O} 2+\mathrm{H})\end{array}$ & $\begin{array}{c}30+70 \\
(\mathrm{O} 2+\mathrm{H})\end{array}$ \\
\hline B & $\begin{array}{c}\text { Pressure of O2+H gas } \\
\text { mixture }\end{array}$ & 20 bar & 24 bar & $28 \mathrm{bar}$ \\
\hline C & $\begin{array}{c}\text { Impulse of the } \\
\text { chamber }\end{array}$ & $100 \mathrm{~mm}$ & $150 \mathrm{~mm}$ & $200 \mathrm{~mm}$ \\
\hline D & Size of the burr & Light burr & Medium burr & Heavy burr \\
\hline
\end{tabular}

A. Mixture ratio of Oxygen and Hydrogen gas is taken from the knowledge of the operator and the supervisor of the thermal deburring machine.

B. The pressure of oxygen and hydrogen gas mixture is taken from 20 bar, 24 bar and 28 bar. 
$20 \mathrm{bar}$ is the minimum pressure that is available in the machine.

24 bar is the middle value of the upper and lower pressure.

$28 \mathrm{bar}$ is the maximum pressure that is available in the machine.

C. Impulse of the chamber can be taken from the $100 \mathrm{~mm}$ to $200 \mathrm{~mm}$.

$100 \mathrm{~mm}$ is the minimum length of the chamber.

$150 \mathrm{~mm}$ is the middle value of the chamber length.

$200 \mathrm{~mm}$ is the maximum length of the chamber.

\section{Size of the burr}

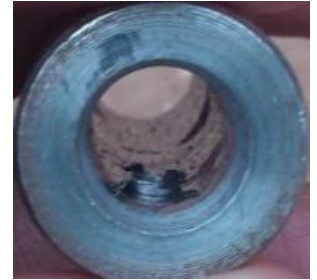

Fig 3(a) Heavy burr

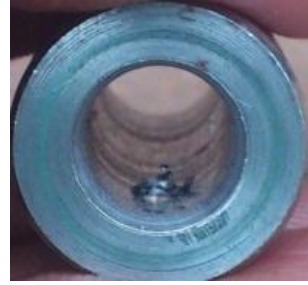

Fig 3(b) Medium burr

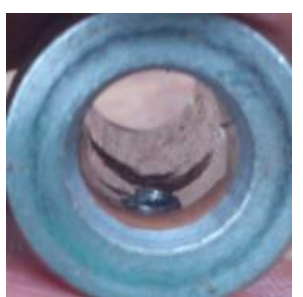

Fig 3(c) Light

burr

\subsection{Selecting an Orthogonal Array:}

For 3 levels and 4 factors $\left(3^{4}\right)$, L9 orthogonal array is selected which consists 9 set of experiments. Table 2 shows the L9OA(Orthogonal array)

Table 2 L9OA for 3 levels and 4 factors
\begin{tabular}{|c|c|c|c|c|}
\hline \multirow{2}{*}{ Exp no } & \multicolumn{5}{c|}{ column } \\
\cline { 2 - 5 } & 1 & 2 & 3 & 4 \\
\hline 1 & 1 & 1 & 1 & 1 \\
\hline 2 & 1 & 2 & 2 & 2 \\
\hline 3 & 1 & 3 & 3 & 3 \\
\hline 4 & 2 & 1 & 2 & 3 \\
\hline 5 & 2 & 2 & 3 & 1 \\
\hline 6 & 2 & 3 & 1 & 2 \\
\hline 7 & 3 & 1 & 3 & 2 \\
\hline $\mathbf{S}$ & 3 & 2 & 1 & 3 \\
\hline 9 & 3 & 3 & 2 & 1 \\
\hline factors & A & B & C & D \\
\hline
\end{tabular}

$\mathbf{A}=$ Mixture ratio of $\mathrm{O} 2+\mathrm{H}, \mathbf{B}=$ Pressure of $\mathrm{O} 2+\mathrm{H}$ gas mixture(bar), $\mathbf{C}=$ Impulse of the chamber $(\mathrm{mm}), \mathbf{D}=$ size of the burr.

The experiment is conducted as per ANOVA table. In each trial 300 barrels are deburred. For each experiment 2 trials were conducted. The number of components accepted after the thermal deburring is noted down.

Table 3 Experimental trial

\begin{tabular}{|c|c|c|c|c|c|c|c|}
\hline \multirow{2}{*}{ Exp no. } & \multicolumn{4}{|c|}{ Factors } & \multicolumn{2}{c|}{$\begin{array}{c}\text { No. Of components } \\
\text { accepted for a batch } \\
\text { of 300 }\end{array}$} & \multirow{2}{*}{$\begin{array}{c}\text { Average of } \\
\text { trials }\end{array}$} \\
\cline { 2 - 7 } & A & B & C & D & Trial 1 & Trial 2 & \\
\hline $\mathbf{1}$ & A1 & B1 & C1 & D1 & 251 & 253 & 252 \\
\hline $\mathbf{2}$ & A1 & B2 & C2 & D2 & 253 & 257 & 255 \\
\hline $\mathbf{3}$ & A1 & B 3 & C 3 & D3 & 233 & 241 & 237 \\
\hline $\mathbf{4}$ & A2 & B1 & C2 & D3 & 241 & 245 & 243 \\
\hline $\mathbf{5}$ & A2 & B2 & C3 & D1 & 258 & 264 & 261 \\
\hline $\mathbf{6}$ & A2 & B3 & C1 & D2 & 252 & 258 & 255 \\
\hline $\mathbf{7}$ & A3 & B1 & C3 & D2 & 247 & 251 & 249 \\
\hline $\mathbf{8}$ & A3 & B2 & C1 & D3 & 250 & 254 & 252 \\
\hline $\mathbf{9}$ & A3 & B3 & C2 & D1 & 272 & 274 & 273 \\
\hline
\end{tabular}




\subsection{Analysis:}

ANOVA table is used for analysis which consists of sum of squares, mean of sum of squares variance and percent contribution i.e., SS, MS, F\&P.

Table 4: sum of trials

\begin{tabular}{|c|c|c|c|}
\hline Experiment no. & Trial 1 & Trial 2 & Sum of trials \\
\hline 1 & 251 & 253 & 504 \\
\hline 2 & 253 & 257 & 510 \\
\hline 3 & 233 & 241 & 474 \\
\hline 4 & 241 & 245 & 486 \\
\hline 5 & 258 & 264 & 522 \\
\hline 6 & 252 & 258 & 510 \\
\hline 7 & 247 & 251 & 498 \\
\hline 8 & 250 & 254 & 504 \\
\hline 9 & 272 & 274 & 546 \\
\hline
\end{tabular}

Total sum of observations, $\mathrm{T}=4554$

Number of experiments, $\mathrm{N}=18$

Average of total sum of observation $\breve{\mathrm{T}}=\frac{\mathrm{T}}{\mathrm{N}}$

$\breve{\mathrm{T}}=4554 / 18=\check{\mathrm{T}} \mathbf{=} \mathbf{2 5 3}$

\subsection{Sum of square:}

The sum of squares is a measure of the deviation of the experimental data from the mean value of the data. Summing each squared deviation emphasizes the total deviation. The sum of squares $\left(\mathrm{SS}_{\mathrm{A}}\right)$ analysis for the factors and total variation is determined in table $\mathbf{5}$.

Total sum of squares, $\mathrm{SS}_{\mathrm{T}}=\left[\sum_{i=1}^{n} Y i^{2}\right]-T^{2} / N$

$\mathrm{SS}_{\mathrm{T}}=251^{2}+253^{2}+253^{2}+257^{2}+233^{2} \ldots \ldots .-\frac{(4554)^{2}}{18}$

$\mathrm{SS}_{\mathrm{T}}=1796$

Table 5 Sum of squares

\begin{tabular}{|c|c|c|c|c|c|c|c|}
\hline \multirow{2}{*}{ Factors } & \multicolumn{3}{|c|}{ Levels } & \multirow{2}{*}{$\begin{array}{l}\text { Number of } \\
\text { experiments }\end{array}$} & \multicolumn{3}{|c|}{ Sum of Squares } \\
\hline & 1 & 2 & 3 & & & & \\
\hline A & 1488 & 1518 & 1548 & 6 & $\mathrm{Ss}_{\mathrm{A}}=$ & {$\left[\sum_{i=1}^{k a}\left(\frac{A i^{2}}{n A i}\right)\right]-\frac{T^{2}}{N}=\frac{A 1^{2}}{n A 1}+\frac{A 2^{2}}{n A 2}+\frac{A 3^{2}}{n A 3}-\frac{T^{2}}{N}$} & $=300$ \\
\hline B & 1488 & 1536 & 1530 & 6 & $\mathrm{SS}_{\mathrm{B}}=$ & {$\left[\sum_{i=1}^{k b}\left(\frac{B i^{2}}{n B i}\right)\right]-\frac{T^{2}}{N}=\frac{B 1^{2}}{n B 1}+\frac{B 2^{2}}{n B 2}+\frac{B 3^{2}}{n B 3}-\frac{T^{2}}{N}$} & $=228$ \\
\hline $\mathrm{C}$ & 1518 & 1542 & 1494 & 6 & $\mathrm{SS}_{\mathrm{C}}=$ & {$\left[\sum_{i=1}^{k c}\left(\frac{C i^{2}}{n C i}\right)\right]-\frac{T^{2}}{N}=\frac{C 1^{2}}{n C 1}+\frac{C 2^{2}}{n C 2}+\frac{C 3^{2}}{n C 3}-\frac{T^{2}}{N}$} & $=192$ \\
\hline $\mathrm{D}$ & 1572 & 1518 & 1464 & 6 & $\mathrm{SS}_{\mathrm{D}}=$ & {$\left[\sum_{i=1}^{k d}\left(\frac{D i^{2}}{n D i}\right)\right]-\frac{T^{2}}{N}=\frac{D 1^{2}}{n D 1}+\frac{D 2^{2}}{n D 2}+\frac{D 3^{2}}{n D 3}-\frac{T^{2}}{N}$} & $=972$ \\
\hline
\end{tabular}

Error,

Since, $\mathrm{SS}_{\mathrm{T}}=\mathrm{SS}_{\mathrm{A}}+\mathrm{SS}_{\mathrm{B}}+\mathrm{SS}_{\mathrm{C}}+\mathrm{SS}_{\mathrm{D}}+\mathrm{SSe}$

$\mathrm{SSe}=\mathrm{SS}_{\mathrm{T}}-\mathrm{SS}_{\mathrm{A}}-\mathrm{SS}_{\mathrm{B}}-\mathrm{SS}_{\mathrm{C}}-\mathrm{SS}_{\mathrm{D}}$

$\mathrm{SSe}=1796-300-228-192-972$

$\mathrm{SSe}=104$. 
4.5 Degree of freedom (DOF):

Total degree of freedom, $\mathrm{V}_{\mathrm{T}}=\mathrm{N}-1$

$\mathrm{V}_{\mathrm{T}}=18-1=17$

Table 6: Degree of Freedom

\begin{tabular}{|c|c|}
\hline Factors & DOF \\
\hline $\mathrm{A}\left(\mathrm{V}_{\mathrm{A}}\right)$ & 2 \\
\hline $\mathrm{B}\left(\mathrm{V}_{\mathrm{B}}\right)$ & 2 \\
\hline $\mathrm{C}\left(\mathrm{V}_{\mathrm{C}}\right)$ & 2 \\
\hline $\mathrm{D}\left(\mathrm{V}_{\mathrm{D}}\right)$ & 2 \\
\hline
\end{tabular}

For error, $\mathrm{V}_{\mathrm{e}}$

$\mathrm{Ve}=\mathrm{V}_{\mathrm{T}}-\mathrm{V}_{\mathrm{A}}-\mathrm{V}_{\mathrm{B}}-\mathrm{V}_{\mathrm{C}}-\mathrm{V}_{\mathrm{D}}=9$

4.6 Mean square deviation(MS):

Mean square deviation is the ratio of sum of squares to the degrees of freedom of the respective data.

Table 7: Mean square deviation

\begin{tabular}{|c|cc|}
\hline Factors & Mean square deviation \\
\hline $\mathrm{A}$ & $\mathrm{MS}=\frac{S S A}{V A}$ & $=150$ \\
\hline $\mathrm{B}$ & $\mathrm{MS}$ B $=\frac{S S B}{V B}$ & $=114$ \\
\hline $\mathrm{C}$ & $\mathrm{MSC}=\frac{S S C}{V C}$ & $=96$ \\
\hline $\mathrm{D}$ & $\mathrm{MSD}=\frac{S S D}{V D}$ & $=486$ \\
\hline Error & $\mathrm{MSe}=\frac{S S e}{V e}$ & $=11.55$ \\
\hline
\end{tabular}

\subsection{F-test/ Variance ratio:}

F-test/ variance is used to measure the significance of the factor under investigation with respect to the mean square of all the factors included in the error term.

Table 8: F-test/ Variance ratio

\begin{tabular}{|c|ll|}
\hline Factors & \multicolumn{3}{|c|}{ F-test/variance ratio } \\
\hline $\mathrm{A}$ & FA $=\frac{M S_{A}}{M S_{e}}=13.04$ \\
\hline $\mathrm{B}$ & $\mathrm{FB}=\frac{M S_{B}}{M S_{e}}=9.9$ \\
\hline $\mathrm{C}$ & $\mathrm{FC}=\frac{M S^{\circ}}{M S_{e}}=8.34$ \\
\hline $\mathrm{D}$ & FD $=\frac{M S_{D}}{M S_{e}}=42.27$ \\
\hline
\end{tabular}

\subsection{Pure sum of squares:}

Factor i, $\mathrm{SS}_{\mathrm{i}}=\mathrm{SSi}-(\mathrm{MSe} \times \mathrm{Vi})$, where $\mathrm{i}=\mathrm{A}, \mathrm{B}, \mathrm{C}, \mathrm{D}$

Table 9: Pure sum of squares

\begin{tabular}{|c|c|}
\hline Factors & Pure sum of squares \\
\hline A & 277 \\
\hline B & 205 \\
\hline C & 169 \\
\hline D & 949 \\
\hline
\end{tabular}




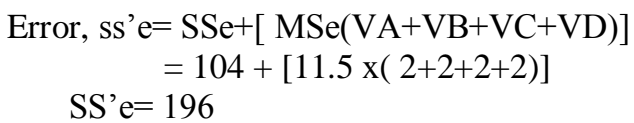

\subsection{Percentage contribution:}

The percentage contribution for any factor is obtained by dividing the pure sum of squares for that factor by Total Sum of Squares and multiplying the result by 100. The percentage contribution is denoted by P and can be calculated using the following equations.

Table 10: Percentage contribution

\begin{tabular}{|c|c|}
\hline Factor & Percentage contribution \\
\hline $\mathrm{A}$ & $\mathrm{PA}_{\mathrm{A}}=\frac{S S^{\prime} A}{S S T} \times 100=15.42 \%$ \\
\hline $\mathrm{B}$ & $\mathrm{PB}=\frac{S S^{\prime} B}{S S T} \times 100=11.41 \%$ \\
\hline $\mathrm{C}$ & $\mathrm{PC}=\frac{S S^{\prime} C}{S S T} \times 100=9.4 \%$ \\
\hline $\mathrm{D}$ & $\mathrm{PD}=\frac{S S^{\prime} D}{S S T} \times 100=52.8 \%$ \\
\hline Error & $\mathrm{Pe}_{\mathrm{e}}=\frac{S S^{\prime} e}{S S T} \times 100=10.91 \%$ \\
\hline
\end{tabular}

Table 11: ANOVA

\begin{tabular}{|c|c|c|c|c|c|c|}
\hline Factors & $\begin{array}{c}\text { Degree of } \\
\text { freedom }\end{array}$ & $\begin{array}{c}\text { Sum of } \\
\text { Squares }\end{array}$ & $\begin{array}{c}\text { Mean Square } \\
(\mathrm{MS})\end{array}$ & $\mathrm{F}$ & $\begin{array}{c}\text { Pure sum } \\
\text { SS }\end{array}$ & $\begin{array}{c}\text { Percentage } \\
\text { contribution } \\
(\%)\end{array}$ \\
\hline $\mathrm{A}$ & 2 & 300 & 150 & 13.04 & 277 & 15.42 \\
\hline $\mathrm{B}$ & 2 & 228 & 114 & 9.9 & 205 & 11.41 \\
\hline $\mathrm{C}$ & 2 & 192 & 96 & 8.34 & 169 & 9.4 \\
\hline $\mathrm{D}$ & 2 & 972 & 486 & 42.26 & 949 & 52.8 \\
\hline Err & 9 & 104 & 11.5 & - & 196 & 10.91 \\
\hline Tot & 17 & 1796 & 857.5 & 73.54 & 1796 & 99.94 \\
\hline
\end{tabular}

\subsection{Signal to Noise ratio(S/N ratio):}

Taguchi has created a transformation of the repetition data to another value that reflects the amount of variation present. The transformation is the signal to noise ratio. The higher value of $S / N$ ratio is always desirable because greater $S / N$ ratio will result in smaller product variance around the target value.

For Larger the better-type

$\mathrm{S} / \mathrm{N}=-10 \log 10(\mathrm{MSD})$

Mean Square Deviation,

$\operatorname{MSD}=1 / \mathrm{n} \quad \sum_{i=1}^{n} \frac{1}{(y 1)^{2}}+\frac{1}{(y 2)^{2}}+\frac{1}{\left(y_{3}\right)^{2}}$

Sum of Squares, $\mathrm{SS}=\sum\left(\frac{1}{y^{2}}+\frac{1}{y 2^{2}}+\ldots\right)$

Where the $n=$ number of repetition, $y=$ value 
Table 12: Signal to Noise ratio

\begin{tabular}{|c|c|c|c|}
\hline Sl. no & Sum of square & $\begin{array}{c}\text { Mean square } \\
\text { deviation }\end{array}$ & S/N ratio \\
\hline $\mathbf{1}$ & $3.14 \times 10^{-05}$ & $1.57 \times 10^{-05}$ & 48.04 \\
\hline $\mathbf{2}$ & $3.07 \times 10^{-05}$ & $1.53 \times 10^{-05}$ & 48.15 \\
\hline $\mathbf{3}$ & $3.56 \times 10^{-05}$ & $1.78 \times 10^{-05}$ & 47.495 \\
\hline $\mathbf{4}$ & $3.38 \times 10^{-05}$ & $1.69 \times 10^{-05}$ & 47.721 \\
\hline $\mathbf{5}$ & $2.93 \times 10^{-05}$ & $1.465 \times 10^{-05}$ & 48.341 \\
\hline $\mathbf{6}$ & $3.07 \times 10^{-05}$ & $1.535 \times 10^{-05}$ & 48.138 \\
\hline $\mathbf{7}$ & $3.22 \times 10^{-05}$ & $1.61 \times 10^{-05}$ & 47.931 \\
\hline $\mathbf{8}$ & $3.15 \times 10^{-05}$ & $1.575 \times 10^{-05}$ & 48.04 \\
\hline $\mathbf{9}$ & $2.68 \times 10^{-05}$ & $1.34 \times 10^{-05}$ & 48.72 \\
\hline
\end{tabular}

4.11 Factors and their individual levels affecting the thermal deburring process are calculated from the L9OA

Table 13: Factors and their levels affecting

\begin{tabular}{|c|c|c|c|}
\hline Factors & Level 1 & Level 2 & Level 3 \\
\hline A & 248 & 253 & 258 \\
\hline B & 247 & 256 & 255 \\
\hline C & 253 & 257 & 249 \\
\hline D & 262 & 253 & 244 \\
\hline
\end{tabular}

For factor A, level 1

$(\mathrm{Ex} 1+\mathrm{Ex} 2+\mathrm{Ex} 3) / 3=(252+255+237) / 3=248$

Similarly

For factor A, level 2

$(\mathrm{Ex} 4+\mathrm{Ex} 5+\mathrm{Ex} 6) / 3=(243+261+255) / 3=253$

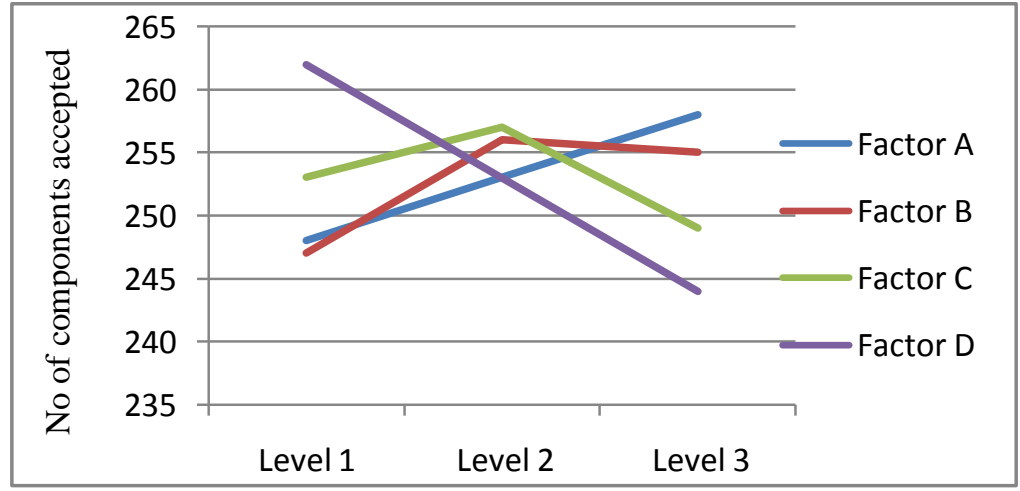

Fig. 4 showing number of components accepted in thermal deburring Vs Factors values as per calculation.

From the above graph we the result that A3 B2 C2 D1 are the optimal process parameters for thermal deburring. 


\subsection{Verification experiment:}

After determining the optimum conditions and predicting the response under these conditions, there is an experiment conducted with the optimum parameters and that results are compared with the predictions.

Table 14: Verification experiment

\begin{tabular}{|c|c|c|c|c|c|c|c|}
\hline \multirow{2}{*}{$\begin{array}{c}\text { Exp. } \\
\text { no. }\end{array}$} & \multicolumn{4}{|c|}{ Factors } & \multicolumn{2}{c|}{$\begin{array}{c}\text { No. Of components } \\
\text { accepted for a batch of 300 } \\
\text { numbers }\end{array}$} & \multirow{2}{*}{$\begin{array}{c}\text { Average } \\
\text { of trials }\end{array}$} \\
\cline { 2 - 7 } & A & B & C & D & Trial 1 & Trial 2 & \\
\hline 1 & A3 & B2 & C2 & D1 & 275 & 277 & 276 \\
\hline
\end{tabular}

\section{RESULTS AND DISCUSSION}

Thermal deburring process in thermal deburring machine, the varying controllable factors are Mixture ratio of Oxygen \& Hydrogen gas, Pressure of Oxygen \& Hydrogen gas mixture, Impulse of the chamber and Size of the burr. For the four factors and three levels $3^{\wedge}(4)$ the Taguchi's L9 Orthogonal Array is selected and the experiment is conducted. Two sets of trials were conducted for each experiment and in each trial 300 components are deburred. The trials results are shown the table 3. Analysis is done through ANOVA procedure and tabulated in table 11. The parameters A3 B2 C2 D1 are found to be optimal process parameters. From table 11 it is evident that size of the burr contributes more in thermal deburring by $52.8 \%$.

\section{CONCLUSION}

The thermal deburring process with major factors affecting are selected as Mixture ratio of Oxygen \& Hydrogen gas, Pressure of Oxygen \& Hydrogen gas mixture, Impulse of the chamber and Size of the burr, at three different levels are used for conducting the experiment to obtain the optimum condition for thermal deburring process using DOE with Taguchi's method techniques and also the Analysis is carried out using the ANOVA procedure and also the S/N ratio is used for the larger the better type. From all these experiments, calculation and results it is known that out of the four major selected parameters the size of the burr will contribute more in the thermal deburring process. That is with ratio of $30+70(\mathrm{O} 2+\mathrm{H})$ gas mixture and then with 24 bar pressure of $\mathrm{O} 2+\mathrm{H}$ gas mixture, with $150 \mathrm{~mm}$ impulse of the chamber and with light burr the optimum thermal deburring process can be achieved on the thermal deburring machine.

\section{REFERENCES}

[1] Ko, S.L.; Dornfeld, D.A., “A study on burr formation mechanism”, Journal of Engineering materials and technology, Vol.111, 1991, pp.75-87.

[2] Balasubramaniam, R., Krishnan, J., Ramakrishnan, N., “Investigation of AJM for deburring”, Journal of Materials Processing Technology, Vol. 79, 1998, pp. 52-58.

[3] Dornfeld, D.A., Lisiewicz, V, “Acoustic emission feedback for precision deburring”, Annals of the CIRP, Vol. 41, 1992, No. 1, pp. 93-96

[4] ASM Handbook Volume 16, Machining,1990, pp 577-578.

[5] Kennametal Extrude Hone, GmbH. Pvt. Ltd.

[6] www.extrudehone.com.

[7] John Halladay, Precision Machined Products Association National technical seminar, 2011.

[8] Acherjee, B., Kuar, A. S., Mitra, S., Misra, D.,. Selection of process parameters for optimizing the weld strength in laser transmission welding of acrylics, Proc. IMechE Part B: Journal of Engineering Manufacture, SAGE Publications (UK),2010, 224(B10), 1529-1536

[9] S.L. Ko, Yu M. Baron, J.I. Park, "Micro deburring for precision parts using magnetic abrasive finishing method". Journal of Materials Processing Technology 187-188 (2007) 19-25.

[10] Leo Rakowski, Editor ,Production Machining, 11/1/2003

[11] E. Kerscher, K.-H. Lang ."Increasing the fatigue limit of a high-strength bearing steel by a deep cryogenic treatment", 15th International Conference on the Strength of Materials (ICSMA-15), 2010.

[12] Gillespie 1999, p. 11, Nontraditional manufacturing processes,

[13] S. Sarkar, S. Mitra, B. Bhattacharyya. "Mathematical modeling for controlled electrochemical deburring (ecd)". Journal of Materials Processing Technology 147 (2004) 241-246

[14] Taguchi, G., (1991). Taguchi methods. Research and development, Vol. 1. MI: American Suppliers ,Institute Press, Dearborn. 
